\title{
Web Sayfasına Güven ve Canlı Desteğin Yeniden Satın Alma Niyeti Üzerine Etkisi: Online Alışveriş Siteleri Üzerine Bir Araştırma
}

\author{
Emine AYDINHAN*, Serhat ERAT**
}

Öz

Her geçen gün internetin kullanımının artması, kullanıcıların internetten 7/24 alışveriş yapabiliyor olmaları online mağazaların da artmasına yol açmıştır. Elektronik ticaretin giderek yaygınlaşması, online ortamda rekabeti de artırmaktadır. Bu durum işletmeleri kullanıcıları elde tutmak için yollar aramaya sevk etmiştir. Yani işletmeler açısından yeniden satın alma kavramı önem kazanmıștır. Online alışverişte müşterilerin yeniden satın alım yapmalarının sağlanması, işletmelerin yeni müşteri bulma çabalarından daha az maliyetlidir. Dolayısıyla kullanıcılar için önemli olan web sayfasına güven kavramı ve her zaman iletișime geçebilecekleri bir müșteri temsilcisi bulma kavramlarının yeniden satın almaya etkisi önem kazanmıştır. Bu çalışmada, web sayfasına güven ve canlı desteğin yeniden satın alma niyeti üzerindeki etkisinin ne ölçüde olduğu ve aralarında nasıl bir ilişki olduğu temel olarak 6 hipotez sınaması aracılığıyla incelenmektedir. Araştırma internetten alışveriş yapan 346 kiși üzerinde anket aracılığıyla gerçekleștirilmiștir. Araştırma sonuçları incelendiğinde canlı destek, web sayfasına güven ve yeniden satın alma niyeti arasında pozitif ilişkiler bulunmuş olup, ortaya konulan hipotezler doğrulanmıştır.

Anahtar Kelimeler: Web Sayfasına Güven, Canlı Destek, Canlı Destek Güveni, Yeniden Satın Alma Kararı, Algılanan Yarar

\section{The Impact of Trust and Live Support on the Web Page on the Re-Purchase Intention: A Research on Online Shopping Sites}

\section{Abstract}

The rise of daily internet use and chance of $24 / 7$ online shopping resulted increase of online stores. The gradual wide-spread of electronic commerce increased competition on online environment, too. This situation lead business to search ways to keep users. As a result, the value of re-purchasing increased a lot for businesses. Ensuring repurchase on online shopping is less costly than to find new customers.

Özgün Araştırma Makalesi (Original Research Article)

Geliş/Received: 26.08 .2019

Kabul/Accepted: 25.10 .2019

DOI: http://dx.doi.org/10.17336/igusbd.611492

*Yüksek Lisans Öğrencisi, Gebze Teknik Üniversitesi, İșletme Fakültesi, Strateji Bilimi Bölümü, Kocaeli, Türkiye, E-posta: emineaydinhann@gmail.com, ORCID ID https://orcid.org/0000-00020479-2506

${ }^{* *}$ Dr. Öğr. Üyesi, Gebze Teknik Üniversitesi, İşletme Fakültesi, Strateji Bilimi Bölümü, Kocaeli, Türkiye, E-posta: erat@gtu.edu.tr, ORCID ID https://orcid.org/0000-0003-0227-8914 
Therefore, trust of users to a web page and provided communication opportunities to them with a customer representative (live support) at all times became much more important on repurchase decisions. In this study, effects of trust to a web page and provided live support on repurchase decisions, and the relation between them are examined through six hypotheses testing. For the study, 346 people, who made online purchases, are surveyed. Results of the study confirm the conducted hypotheses and show positive relation between live support, web page trust and repurchasing decision.

Keywords: Web Page Trust, Live Support, Live Support Trust, Repurchase Decision, Perceived Benefit

\section{Giriș}

Ekonominin ticari boyutu olan e ticaret internetin ticari amaçlarla kullanılmasıdır. Hem tüketiciler hem de üreticiler tarafından çabuk benimsenmiş ve hızla gelişmiştir (Coşkun, 2004). E-ticaretin hızla benimsenmesi ve gelişmesi, işletmelerin bu alana daha fazla yönelmelerini sağlamaktadır. Türkiye'de e-ticaret sektörü en hızlı büyüyen sektörlerden biridir (Demirdöğmez, Gültekin, \& Taș, 2018). Türkiye İstatistik Kurumu'nun (TÜİK) yaptığı Hane Halkı Bilişim Teknolojileri Kullanım Araştırması verileri incelendiğinde 2017 yılında internet kullanıcılarının kişisel kullanımları için online alışveriş sitelerinden mal veya hizmet sipariş etme ya da satın alma oranı 24,9 iken, 2018 yılında 29,3'e ulaşmaktadır (TÜİK, 2018). Bu veriler online alışverișin giderek daha da arttığının kanıtıdır.

E-ticaret işletmeleri müşteri çekebilmek ve devamlılığını sağlayabilmek için, müşterilerin aklında olan belirsizlikleri ve soruları gidermek durumundadırlar. Bunun için güven ve müşteri ile anında iletişim kurma konularında kendilerini geliştirmeleri gerekmektedir. İnternetten alışveriş yaparken kullanıcıların verdikleri bilgilerin (kredi kartı bilgileri vb.) güvende olduğuna, üçüncü şahısların eline geçmeyeceğine güvenmesi, yani web sitesine güvenmesi gerekmektedir. Mevcut çalışmalar online alışverişte satın alım sırasında müşterilerin algısında birçok belirsizlik olduğunu vurgulamaktadır. $\mathrm{Bu}$ belirsizlikler güveni etkilemektedir.

Yeniden satın alım e-ticaret sitesinin başarılı olabilmesi için kritik bir öneme sahiptir. Çünkü yeni müşteriler elde etmeye çalışmak mevcut müşteriyi elde tutmaktan çok daha maliyetlidir. Müşteriyi elde tutmak rekabet avantajı sağlamaktadır (Tsai \& Huang, 2007). Fakat çevrimiçi ziyaretçilerin sadece \%1'i yeniden aynı siteden satın alım yapmaktadır (Gupta \& Kim, 2007). Bu nedenle, çevrimiçi müşteri yeniden satın alma davranışını yönlendirmek önemlidir (Qureshi et al., 2009).

Bu çalışmada online web sitelerine güven ve canlı desteğin yeniden satın alma niyeti ile ilişkisini tespit etmek amaçlanmaktadır. Çalışmada öne web sayfasına güven, canlı destek ve yeniden satın alma niyetinden söz edilmekte, günümüze kadar yapılan çalışmalar hakkında bilgiler verilmektedir. Araştırma kısmında ise internetten alışveriş yapan kullanıcılarla yapılan anket çalışmasının bulgularına ve analizine yer verilmektedir.

\section{Teorik Altyapı \\ 2.1. Web Sayfasına Güven}

Literatür incelendiğinde güven kavramı, uzun vadeli ilişkiler kurmada ve bu ilișkileri devam ettirmede etkili olan en temel faktörlerden biridir (Sharma \& Patterson, 2000). Güven kavramı literatürde daha önce "dürüstlük, hayırseverlik, yeterlilik, 
Emine Aydınhan, Serhat Erat, “Web Sayfasına Güven ve Canlı Desteğin Yeniden Satın Alma Niyeti Üzerine Etkisi: Online Alışveriş Siteleri Üzerine Bir Araştırma", İstanbul Gelişim Üniversitesi Sosyal Bilimler Dergisi, 6 (GELIŞiM-UWE 2019 Özel Sayısı), Ekim 2019, ss. 123-140.

öngörülebilirlik" kavramları ile tanımlanmaktadır (McKnight, Choudhury, \& Kacmar, 2002). Bir başka deyișle güven, aktörlerin birbirleriyle ilgili inançlarıdır ve her biri güvenilir, etik ve sosyal olarak uygun bir şekilde davranır (Kumar, Scheer, \& Steenkamp, 1995). Güvenin ilişkilerde olumlu tutum oluşturmada önemli rol oynadığı kabul edilmektedir (Anderson \& Weitz, 1992). Özellikle elektronik ticaret sitelerinde güven kavramı hem satıcı hem de alıcı açısından çok önemlidir. Yani siparişin ilk gönderiminden ödemenin tamamlanmasına kadar olan süreçte satıcı da alıcı da kendini güvende hissetmelidir (Altınıșık \& Bilge, 2001). Bir satıcıyla olan ilişki satıcı güvenilir olduğunda daha caziptir. Güvenilir satıcı kelimesi satıcının üzerine düşen tüm yükümlülükleri yerine getireceği inancını doğurur (Schurr \& Ozanne, 1985). Web sitelerinde ve e-ticarette güvenli olduğunu hissettiren, kullanıcıları siteye bağlayan ve memnun eden işletmeler başarılıdır (C. Liu \& Arnett, 2000).

Güvenlik ve gizlilik web siteleri için önemli değerlendirme kriterleridir (Culnan \& Armstrong, 1999; Hoffman \& Novak, 1996; Hoffman, Novak, \& Peralta, 1999; Montoya-Weiss, VOSS, \& Grewal, 2000). Bu iki kriter için en önemli ayrım; web sayfası gizliliği kişisel verilerin diğer sitelerle paylaşılmamasını kapsarken (Friedman, Khan Jr, \& Howe, 2000), güvenlik kullanıcıların kredi kartı gibi finansal bilgilerinin kullanımından kaynaklı sahtecilik ve finansal kayıplardan korumayı içerir (MontoyaWeiss et al., 2000).

\subsection{Canlı Destek}

Rol teorisine göre bireyler belli durumlarda belli bir hizmet kalitesi beklerler (Solomon, Surprenant, Czepiel, \& Gutman, 1985). Bu sebeple kullanıcılar çevrimdıșı ortamda da olduğu gibi, çevrimiçi ortamda da teknolojik kıstaslara bakılmaksızın belli hizmetlerle karşılaşma olanağına sahip olmayı bekler (Tombs \& McColl-Kennedy, 2003). Toplumsal/sosyal buradalık (social presence) kuramına dayanan önceki araştırmalar, kullanıcların web sitelerini bir kanal veya ortam olarak görmelerinden ziyade sosyal aktör olarak gördüklerini vurgulamaktadır (A. Lee \& Jeong, 2010). Dolayısıyla kișiselleștirilmiş hizmetlerin geliștirilmesiyle web tabanlı müșteri desteğine önem verilmiştir (Cenfetelli, Benbasat, \& Al-Natour, 2008). Canlı destek sistemi web sitelerinde müşterilerin anında iletişime geçerek sorularının yanıtlanabileceği bir sistemdir. E-ticaret sitelerinde müșterilerin yaşadığı zorluklardan biri satış sırasında veya satış sonrasında destek alabilecekleri bir kişiye ulaşamamalarıdır. İşletmeler canlı destek sistemi ile bu sorunu çözerek müşterilere anında cevap vermeyi amaçlamaktadır (Yıldırım, 2017). İnternetten yapılan alışverişlerde müşteri satın alacağı ürünü ele alıp inceleme fırsatı bulamamaktadır. Dolayısıyla web sitesinde sunulan görseller, bilgiler ve canlı destek sistemi ile sağladıkları bilgilere dayanarak karar vermektedirler (Mavlanova \& Benbunan-Fich, 2010).

Canlı destek servisleri genellikle şirketin sunduğu hizmetle ilgili bilgi arayan müşteriye cevapları veren müşteri temsilcileri içermektedir. Örneğin; Çevrimiçi seyahat şirketleri müşterilere faturalandırma, rezervasyon vb. konularda bilgi sağlamak için web tabanlı sohbet araçları sunarlar (Turel \& Connelly, 2013). Birçok kuruluş müșterilere, sorunların üstesinden gelmek, soruları cevaplamak ve web sitesinde arama ve navigasyonunda yardım etmek için müșteri temsilcisiyle canlı sohbet imkânı sağlar (Turel \& Connelly, 2013). Tüketicilerin online ortamdaki konforunu artırmak için, canlı sohbet temsilcisinin müşterilerin sorularını yanıtlamak için müșterilerle konuşmaya hazır olması gerekir. Bu bağlamda, Forrester Research, çevrimiçi alışveriş sitelerinde alışveriş yapanların \%44'ünün soruları yanıtlamaya hazır bir canlı destek sisteminin bulunduğunu belirtti ve bir web sitesinin sağlayabileceği en önemli özelliklerden biri olduğunu keşfetti. Fiili satın alma davranışı söz konusu olduğunda, müşterilerin \%38'i 
canlı destek oturumları sayesinde çevrimiçi işlemler gerçekleştirmektedir. Diğer taraftan, müşterilerin canlı sohbet ile görüșeceği ihtiyaçları; siparişin durum bilgisini almak, 'iade politikaları' hakkında soru sormak, hizmetlerle ilgili geri bildirimde bulunmak ve önerilerde bulunmak șeklinde sıralanabilir. Canlı sohbetin bir diğer faydası, çok sayıda müşterinin sorununa karşı çözüm ürettiğinden şirketin müşteriler tarafından anında değerlendirmeler almasıdır. Canlı destek sistemi bir online alışveriş sitesinin başarılı olması için büyük önem taşımaktadır (Kim, Suh, \& Lee, 2013).

\subsubsection{Güven}

Tüketicilerle iş birliği ve iletişim içinde olunması güven duygusunu artırmaktadır. $\mathrm{Bu}$ sebeple müșterilere iletişim kurabilme ve bilgi alışverişinde bulunabilme olanağı sunulmalıdır (Dayal, Landesberg, \& Zeisser, 2003). Kullanıcıların sanal mağazalarla etkileșim kurabilmeleri duyduklarını güveni etkilemektedir (McKnight et al., 2002). Müşteriler canlı destek temsilcilerinin bilgi ihtiyaçlarını karşılayacak yetkinlikte ve güvenilir bilgiler sağlamalarını beklemektedir (Flanagin \& Metzger, 2007). Bir servis temsilcisinden bilgilerin kalitesi konusunda güvence almak, hizmet kalitesinin önemli bir boyutudur (Anantharanthan Parasuraman, Berry, \& Zeithaml, 1991). Ayrıca müșteri temsilcisinden alınan hızlı yanıt ve işlemlerin web sayfası güvenilirliğini artırdığı görülmektedir (Fogg et al., 2001).

\subsubsection{Algilanan Yarar}

Önceki araştırmalar, bireylerin bilgili bir servis sağlayıcıdan bilgi toplamak ve webde yapılan işleme ayrılan süreyi kısaltmak için sıklıkla canlı sohbet olanaklarını kullandıklarını belirtmektedir (Chattaraman, Kwon, \& Gilbert, 2012; McLean \& Wilson, 2016; Turel \& Connelly, 2013). Canlı destek sistemi aynı anda birden fazla müșteriye cevap sağlaması açısından pratik ve ekonomik bir yöntemdir (Yıldırım, 2017). Web tabanlı servis temsilcisinin sağladığı yüksek kaliteli bilgiler, bir müşterinin o sitedeki tecrübesinin memnuniyetle sonuçlanmasında etkili olacaktır (McLean \& Osei-Frimpong, 2017).

\subsection{Yeniden Satın Alma Niyeti}

Yeniden satın alma, bir ürün veya hizmeti müşterinin aynı şirketten birden fazla satın alma konusundaki yargısıdır (Hellier, Geursen, Carr, \& Rickard, 2003). Çevrimiçi perakendecilik bağlamında yeniden satın alma niyetleri belirli bir perakendeciden satın almak için çevrimiçi kanalın yeniden kullanılması olarak tanımlanmaktadır (Khalifa \& Liu, 2007). Online satın almayı genel anlamda iki aşamaya ayrılmaktadır. İlki kullanıcıları online satın almaya teşvik etmek. İkincisi ise aynı grubu yeniden satın almaya teşvik etmektir. İkinci aşamayı gerçekleştiren e-perakendeci başarılıdır. Çünkü yeni müșteriler elde etmek, mevcut müşterinin yeniden satın almasını sağlamaktan daha fazla zaman ve emek gerektirir. Aynı zamanda yeniden satın alım pazar payındaki büyümeyi sağlayan araçlardan biridir (Ahmed, Shaukat, Nawaz, Ahmed, \& Usman, 2011; Reichheld \& Sasser, 1996; Shin, Chung, Oh, \& Lee, 2013). Sum Chau and Kao (2009) hizmet kalitesi boyutlarını tartıştılar ve bu boyutların kullanıcıların hizmet değerlendirmesinde ve yeniden satın alma niyetleri üzerinde önemli bir etkiye sahip olduğunu keşfettiler. Algılanan kullanım kolaylığı, algılanan fayda, gizlilik, güvenilirlik ve hizmet kalitesinin işlevselliği, çevrimiçi yeniden satın alma niyeti ile pozitif yönde ilişkilidir (Cheng \& Huang, 2013; Chiu, Chang, Cheng, \& Fang, 2009; Har Lee, Cyril Eze, \& Oly Ndubisi, 2011). Ayazlar and Yüksel (2012) tüketici güveni arttıkça bilişsel çelişki 
azalacağını ve yeniden satın alma niyetinin artacağını belirtmektedir. Güvenin yeniden satın alma niyetini doğrudan ve bilişsel çelişki ile dolaylı yoldan etkilediğini öne sürmektedirler.

\subsubsection{Satın Alma Niyeti}

Niyet kavramı genel olarak eylemi gerçekleștirmeden önce eylemi yapmayı planlama veya tasarlama anlamına gelmektedir. Niyet bir davranışı gerçekleștirmeden önce o davranışı yapmaya yönelik fiili iradenin göstergesi olduğu için, davranışı gerçekleştirmede önemli rol oynamaktadır. Satın alma niyeti ise tüketicilerin gelecekte bir ürünü veya hizmeti satın alma olasılığıdır (Zeren \& Gokdagli, 2017). Satın alma niyeti, satın alma karar sürecinin en kritik noktalarından biridir (Kumar et al., 1995). Literatürde satın alma üzerinde birçok model geliștirilmiştir. Bunlardan bazıları ekonomik model, psiko-ekonomik model ve sosyo-ekonomik modeldir. Ekonomik modele göre tüketici istek ve ihtiyaçlarını karşılayacak ürün veya hizmeti sınırlı bir miktar para ile tatmin olacak şekilde kendi rasyonel seçimini yaparak satın alır. Psikoekonomik modele göre tüketicinin güdüleri, geleceğe yönelik davranışları ve alışkanlıkları ekonomik etkenler kadar önemlidir. Sosyo-ekonomik modelde ise tüketicinin içinde bulunduğu sosyal çevre, sosyal statü, toplumsal sınıf satın alma kararında etkilidir (Tuğcu, 2003). Tüketici satın alma öncesinde bilgi arama, diğer seçenekleri tanıma, satış sonrası değerlendirme, kullandıktan sonra elden çıkarma gibi seçenekleri değerlendirerek satın alım kararı vermekte veya vermemektedir (Avcl, Baran, \& Özoğul).

\subsubsection{Sadakat Niyeti}

Sadakat genel olarak aynı markayı tekrar satın alma istekliliği olarak tanımlanmaktadır. Müşteri sadakatini sağlamak işletmeler için en zor kısımlardan biridir. Sadakat sağlayabilmek için müșteri memnuniyetini ve güvenini kazanmak durumundadırlar (Erçetin, 2015). Aynı zamanda hizmet kalitesinde yapılan artışlar da sadakatin sağlanmasında yaralı olmaktadır (Eid, 2011). Sadakat niyeti web siteleri için de yine aynı tanımla, müşterilerin elektronik ticaret yapan web sitelerinden almıș oldukları ürün veya hizmetleri, gelecekte yine o siteden satın alma niyeti e-sadakat olarak tanımlanmaktadır (T.-H. Liu, 2012).

\subsection{Değişkenler Arası İlişkiler}

Online ortamda tüketici güveninin artması satın alma niyetini de artırmaktadır (Jarvenpaa, Tractinsky, \& Vitale, 2000). Tüketicilerin güveni, çevrimiçi perakendeciye yönelik satın alma niyetini olumlu yönde etkiler (Hsin Chang \& Wen Chen, 2008). Güven müşteri memnuniyeti ve bağlılığını etkilemektedir (Shiau \& Luo, 2012). Müșterilerin siteye duydukları güven ile memnuniyet doğru orantılıdır. Güven arttıkça müșterinin memnuniyeti de artmaktadır. Dolayısıyla müșteriler güven duydukları online alışveriș sitelerini kullanmayı alışkanlık haline getirmektedirler (Lin \& Wang, 2006). Alışveriş sitesine duyulan güven tüketicilerin yeniden satın alma niyetine sahip olmalarını sağlamaktadır (Gefen, Karahanna, \& Straub, 2003; Grabner-Kraeuter, 2002; M. K. Lee \& Turban, 2001).

Müşteri beklentilerinin sürekli arttığı bu çağda, e-posta iletişimindeki uzun gecikmeler kabul edilemez hale gelmektedir. Birçok müşteri cevapsız bir sorusu dahi olsa satın alma işlemini tamamlama konusunda tereddüt etmektedir. Canlı destek sohbeti, müşterilere gerçek zamanlı olarak anında sorularına yanıt vermekte, bu da 
müşterilerin memnuniyet düzeyini artırmaktadır. Müșteriler sitenizde canlı sohbet düğmesi gördüğünde, satış yapıldıktan sonra bile canlı bir kișiye kolayca erişebileceklerinden emin olmaktadırlar (Elmorshidy, 2013). Srinivasan, Anderson, and Ponnavolu (2002), e-ticaret uygulamalarının etkileşim yönünün, müşteri sadakati ile yakından ilișkili olduğunu kanıtlamaktadırlar.

Canlı sohbet, tüketicilere ürün bilgileri sağlayarak ve satıcılarla iletișim kurarak ürün belirsizliğini azaltmada yardımcı olabilir. Ürün bilgileri için, tüketiciler (bilgi arayanlar olarak), satıcılarla canlı sohbet yoluyla iletișim kurarlar, böylece ürünlerle ilgili önemli bilgiler edinirler. Dolayısıyla belirsizlik giderek azalır. Müşteri üzerindeki etki için canlı sohbet temsilcileri bir yandan semboller (örneğin gülen yüzler ve videolar), samimiyet algısının gelişimini etkilerler (Ou, Pavlou, \& Davison, 2014). Canlı sohbeti etkin bir șekilde kullanmak (örneğin, mizahi bir dil, resimler veya ifadeler kullanmak), tüketiciler ve satıcılar arasında karşılıklı farkındalığı kolaylaștırabilmektedir. Bu da sohbeti geleneksel yüz yüze iletișime benzer hale getirmektedir. Öte yandan, canlı sohbet, ürünü doğrulama ve müzakere süreçlerini hızlandıran ve böylece etkileşimi artıran etkileşimli bir kanal sağlamaktadır (Jiang, Chan, Tan, \& Chua, 2010). Etkileşimin artması ile birlikte güven de artmaktadır (Lu, Fan, \& Zhou, 2016). Güvenin artması da ürün belirsizliklerinin giderilmesine katkıda bulunmaktadır (Pavlou, Liang, \& Xue, 2007). Ürün belirsizliği düzeyi, tüketici niyeti ve gerçek çevrimiçi alışverişler ile negatif ilişkili olduğu için belirsizliklerin giderilmesi niyetlerin kesinleşmesini sağlamaktadır (Adjei, Noble, \& Noble, 2010). Çok sayıda eticaret web sitesi, müşterileri web sitesinde tutmak için canlı sohbet sistemini desteklemektedir. Çünkü canlı sohbetlerin sonucu olarak, müşteriler çevrimiçi alışveriş deneyimine güven duymaktalar ve dönüşüm oranlarında da iyileşmeler olmaktadır. Amerikan Online tarafından yapılan bir ankette, müşterilerinin\% 68'i canlı sohbet oturumlarına katılmakta ve\% 63'ü tekrar satın almak için web sitesine geri dönmektedir (Köksal \& Penez, 2015).

\section{Metodoloji ve Hipotezler 3.1. Araştırma Örneklemi}

Araştırmanın örneklemini interneti kullanan ve internetten alışveriş yapan 346 kişi oluşturmaktadır.

\subsection{Veri Toplama Yöntemi ve Ölçümü}

$\mathrm{Bu}$ araştırmada literatürde sıkça kullanılan veri toplama yöntemi olan "anket" yöntemi kullanılmıştır. 21 soruluk anket formuna online alışveriş sitesine giren 346 kullanıcı kişi katılmıştır. Yine bu araştırma kapsamında, söz konusu değişkeni ölçümlemek amacıyla kullanılan ölçekler așağıdaki gibidir.

Loiacono, Watson, and Goodhue (2002) tarafından geliştirilen WebQual ölçeğinden yararlanılarak 3 ifadeden oluşan Web Sayfası Güven ölçeği kullanılmıştır. McLean and Osei-Frimpong (2017) 'un araștırmasında kullandığı ölçeklerden yararlanılarak Canlı Destek ölçeği kullanılmış ve ölçeğin güven boyutu 4 ifadeden, Algılanan Yarar boyutu ise 5 ifadeden oluşmaktadır. Yeniden Satın Alma Niyeti ise, Yoo and Donthu (2001)'nun geliştirdiği SiteQual ölçeğinden yararlanılarak ve Ananthanarayanan Parasuraman, Zeithaml, and Malhotra (2005)'nın geliştirdiği E-s Qual ölçeğinden yararlanılarak Satın Alma Niyeti 4 İfade ve Sadakat Niyeti 5 ifadeden oluşan iki boyutlu ölçek kullanılmıştır. Ölçekleri oluşturan ifadelerde 5 noktalı likert tipi ölçek soruları yer almıştır (1= Kesinlikle Katılmıyorum 5= Kesinlikle Katılıyorum). 
Ankette aynı zamanda katılımcıların demografik özelliklerini sorgulayan sorular da bulunmaktadır. Demografik özellikler ile ilgili sorular yorgunluktan kaynaklı yanıt sapmalarını önlemek amacıyla anketin en başına konularak ölçümlenmiştir. Ankette bilgi verilmesi istenen demografik özellikler cinsiyet, yaş, eğitim seviyesi, meslek, gelir durumu șeklindedir. Katılımcıların kimlik bilgileri hiçbir șeklide talep edilmemiştir.

\subsection{Araştırmanın Modeli ve Hipotezler}

Yapılan literatür çalışması neticesinde araştırma konusuna bağlı olarak Şekil 1'de ki model kurulmuş ve bu araştırmada altı adet hipotez test edilmektedir.

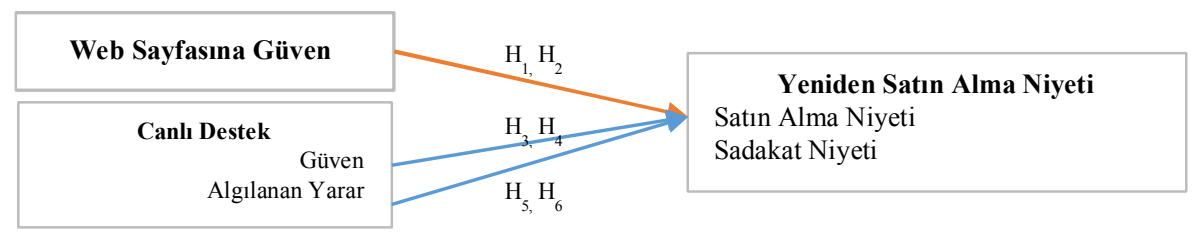

Şekil 1: Araştırma Modeli

\section{Hipotezler}

$\mathrm{H}_{1}$ : Web Sayfasına Güven boyutu Yeniden Satın Alma Niyeti boyutlarından Satın Alma Niyeti boyutunu olumlu etkilemektedir.

$\mathrm{H}_{2}$ : Web Sayfasına Güven boyutu Yeniden Satın Alma Niyeti boyutlarından Sadakat Niyeti boyutunu olumlu etkilemektedir.

$\mathrm{H}_{3}$ : Canlı Destek boyutlarından Güven boyutu Yeniden Satın Alma Niyeti boyutlarından Satın Alma Niyeti boyutunu olumlu etkilemektedir.

$\mathrm{H}_{4}$ : Canlı Destek boyutlarından Güven boyutu Yeniden Satın Alma Niyeti boyutlarından Sadakat Niyeti boyutunu olumlu etkilemektedir.

$\mathrm{H}_{5}$ : Canlı Destek boyutlarından Algılanan Yarar boyutu Yeniden Satın Alma Niyeti boyutlarından Satın Alma Niyeti boyutunu olumlu etkilemektedir.

$\mathrm{H}_{6}$ : Canlı Destek boyutlarından Algılanan Yarar boyutu Yeniden Satın Alma Niyeti boyutlarından Sadakat Niyeti boyutunu olumlu etkilemektedir.

\subsection{Araştırma Bulguları ve Değerlendirme}

Araştırmadaki verilerin analizi SPSS programı kullanılarak sonuçlar elde edilmiştir. Bu kapsamda ilk olarak araştırmaya katılan 346 web sayfası kullanıcısının demografik özelliklerine ilişkin frekans dağılımı Tablo 1'de verilmiştir. 
Emine Aydınhan, Serhat Erat, "Web Sayfasına Güven ve Canlı Desteğin Yeniden Satın Alma Niyeti Üzerine Etkisi: Online Alışveriş Siteleri Üzerine Bir Araştırma", İstanbul Gelişim Üniversitesi Sosyal Bilimler Dergisi, 6 (GELIŞiM-UWE 2019 Özel Sayısı), Ekim 2019, ss. 123-140.

\begin{tabular}{|c|c|c|c|}
\hline & & Frekans & Yüzde $\%$ \\
\hline \multirow[t]{2}{*}{ Cinsiyet } & Erkek & 213 & 62 \\
\hline & Kadın & 133 & 38 \\
\hline Toplam & & 346 & 100 \\
\hline \multirow[t]{4}{*}{ Yaş } & $18-25$ & 138 & 40 \\
\hline & $25-34$ & 133 & 38 \\
\hline & $35-44$ & 48 & 14 \\
\hline & 45 ve üzeri & 27 & 8 \\
\hline Toplam & & 346 & 100 \\
\hline \multirow[t]{4}{*}{ Eğitim Durumu } & İlköğretim & 24 & 7 \\
\hline & Lise & 62 & 18 \\
\hline & Üniversite & 227 & 66 \\
\hline & Lisansüstü & 33 & 9 \\
\hline Toplam & & 346 & 100 \\
\hline \multirow[t]{4}{*}{ Meslek } & Öğrenci & 114 & 33 \\
\hline & Kamu Çalışanı & 39 & 11 \\
\hline & Özel Sektör Çalıșanı & 127 & 37 \\
\hline & Serbest Meslek Çalıșanı & 66 & 19 \\
\hline Toplam & & 346 & 100 \\
\hline \multirow[t]{5}{*}{ Aylık Gelir } & 1000 TL'den az & 123 & 35 \\
\hline & $1000-2000 \mathrm{TL}$ & 67 & 19 \\
\hline & 2001-3000 TL & 61 & 18 \\
\hline & $3001-5000 \mathrm{TL}$ & 62 & 18 \\
\hline & 5000 TL'den fazla & 33 & 10 \\
\hline Toplam & & 346 & 100 \\
\hline
\end{tabular}

Tablo 1: Katılımcıların Demografik Özellikleri

Ankete katılanların \%38' i kadın, \%62 si ise erkektir. Ankete katılanların \%40 1 18-24 yaș, \%38 i 25-34 yaș, \%14 ü 35-44 yaș, \%8 i ise 50-45 yaş ve üzeri arasındadır. Ankete katılanların \%7 si ilköğretim, \%18 i lise, \%66 sı üniversite, \%9 u ise yüksek lisans veya doktora mezunudur. Ankete katılanların \%33 ü öğrenci, \%11 i kamu çalıșanı, \%37 si özel sektör çalıșanı, \%19 u ise serbest meslek çalıșanıdır. Yine ankete katılanların \%35 i 1000TL den az, \%19 u 1000-2000TL arsinda, \%18 i 2001-3000TL arasında, \%18 i 3001-5000TL arasında, \%10 u ise 5000TL den fazla aylık gelire sahiptir. Tablo 1'de ankete katılanların demografik özellikleri verilmiştir.

\subsubsection{Faktör Analizi}

Faktör analizi, yapısal geçerliliğinin test edilmesinde en yaygın kullanılan yöntemlerden biri olarak kabul edilmektedir. Faktör analizi sonucunda kullanılan ölçeği oluşturan soruların kendi aralarında nasıl gruplaştıkları (faktörleri) tespit edilir. Analiz öncesinde faktör analizi gerçekleștirmenin veriye uygunluğunu ölçmek amaciyla Bartlett Küresellik Testi ve Kaiser-Mayer-Olkin (KMO) testleri uygulanmıştır. KMO ve Barlett's küresellik test sonuçları Tablo 2'de verilmiştir.

\begin{tabular}{|l|l|l|}
\hline \multicolumn{2}{|l|}{ Kaiser-Meyer-Olkin Measure of Sampling Adequacy. } &, 939 \\
\hline \multirow{2}{*}{ Bartlett's Test of Sphericity } & Approx. Chi-Square & 8656,302 \\
\cline { 2 - 3 } & Df & 210 \\
\cline { 2 - 3 } & Sig. &, 000 \\
\hline
\end{tabular}

Tablo 2: KMO ve Barlett's Test Sonuçları 
Emine Aydınhan, Serhat Erat, “Web Sayfasına Güven ve Canlı Desteğin Yeniden Satın Alma Niyeti Üzerine Etkisi:

Online Alışveriş Siteleri Üzerine Bir Araştırma", İstanbul Gelişim Üniversitesi Sosyal Bilimler Dergisi, 6 (GELIŞiM-UWE 2019 Özel Sayısı), Ekim 2019, ss. 123-140.

Bulunan KMO değeri 0,939'dur. KMO değeri modelde yer alan değişkenler arasında kısmı korelasyonun düșük olup olmadığını ve örneklemin uygunluğu ifade eder. KMO değeri 0,50'nin üzerinde olmalıdır. 0,5'ten küçük ise, değişken çifti arasındaki korelasyonun diğer değişkenlerle açıklanamayacağını ve faktör analizinin uygun olmayabileceğini ifade eder. Analiz sonucunda elde edilen KMO değeri KMO = 0,939>0,5 olarak bulunmuştur. Kullanılan verilerin faktör analizi için uygun olduğunu göstermektedir.

Ayrıca Barlett's küresellik testi sonucunda elde edilen yaklaşık ki-kare değeri 8656,302 anlamlılık ise 0,000 olarak bulunmuştur. Bu değer korelasyon matrisinin birim matris olduğu şeklindeki sıfır hipotezinin reddedilebildiğini göstermekte ve bu değer verinin faktör analizi yapmak için uygun olduğunu göstermektedir. KMO ve Bartlett'in Küresellik Testi sonuçları Tablo 2'de sunulmuştur.

Değișkenleri olușturan 21 soru keșifsel faktör analizi çalıșmasında beklenen şekilde 5 faktöre ayrılmıştır. Tablo 3'de Faktör Analizi sonuçları verilmiştir. Ortaya çıkan faktörler web sayfasına güven, canlı destek, canlı destek güven, canlı destek algılanan yarar, yeniden satın alma niyeti, satın alma niyeti ve sadakat niyetidir. Açılanan toplam varyans girdi değişkenleri için \%85,404 tur.

\begin{tabular}{|c|c|c|}
\hline \multicolumn{3}{|c|}{ WEB SAYFASINA GÜVEN } \\
\hline 1. & Web sitesindeki işlemlerimde kendimi güvende hissediyorum. & ,788 \\
\hline 2. & Kişisel bilgilerimi güvende tutmak için Web sitesine güveniyorum. & 838 \\
\hline 3. & Web sitesi yöneticilerine, kişisel bilgilerimi kötüye kullanmayacağına & ,777 \\
\hline \multicolumn{3}{|c|}{ CANLI DESTEK } \\
\hline \multicolumn{3}{|c|}{ Güven } \\
\hline 1. & Canlı sohbet temsilcisinin davranışı güven aşılar. & ,703 \\
\hline & $\begin{array}{l}\text { Canlı sohbet temsilcisi ile görüşmelerimde kendimi güvende } \\
\text { m. }\end{array}$ & ,708 \\
\hline 3. & Canlı sohbet temsilcisi sürekli olarak kibar davranır. & ,784 \\
\hline & Canlı sohbet temsilcisi sorularımı cevaplamak için gereken bilgiye & ,690 \\
\hline \multicolumn{3}{|c|}{ Algllanan Yarar } \\
\hline \multicolumn{2}{|c|}{ sağliyor. } & ,778 \\
\hline 2. & Canlı sohbet sistemi performansımı artırıyor & ,795 \\
\hline 3. & Canlı sohbet sistemini kullanmak verimliliğimi arttırıyor. & 848 \\
\hline 4. & Canlı sohbet sistemini kullanmak, etkinliğimi artırıyor. & 835 \\
\hline 5. & Canlı sohbet sistemi faydalıdır. & ,726 \\
\hline \multicolumn{3}{|c|}{ YENIDEN SATIN ALMA NIYETİ } \\
\hline \multicolumn{3}{|c|}{ Satın Alma Niyeti } \\
\hline 1. & Kesinlikle bu siteden yakın gelecekte ürün alacağım. & ,758 \\
\hline 2. & Bu siteden yakın bir gelecekte satın alma yapmayı planlıyorum. & ,788 \\
\hline 3. & Bu siteden yakın bir gelecekte satın alacağım muhtemeldir. & ,802 \\
\hline 4. & Bu siteden yakın bir gelecekte satın alma yapmayı umuyorum. & ,822 \\
\hline \multicolumn{3}{|c|}{ Sadakat Niyeti } \\
\hline 1. & Bu site hakkında insanlara olumlu şeyler söylerim & ,761 \\
\hline 2. & Biri benden tavsiye istediğinde bu siteyi tavsiye ederim & ,795 \\
\hline 3. & Bu siteyle iş yapması için arkadaşlarımı ve başkalarını teșvik ederim. & ,826 \\
\hline 4. & Bu siteyi gelecekteki ișlemler için ilk tercihim olarak düșünürüm. & 807 \\
\hline 5. & Önümüzdeki aylarda bu site ile daha fazla iș yaparım. & ,785 \\
\hline \multicolumn{3}{|c|}{ Açlklanan Toplam Varyans $\quad \% 85,404$} \\
\hline
\end{tabular}

Tablo 3: Faktör Analizi Sonuçları 


\subsubsection{Tüm Değişkenler İçin Korelasyon Analizi}

Korelasyon analizinin amacı bağımsız değişken değiștiğinde, bağımlı değișkenin ne yönde değiștiğini belirlemektir. Tablo 4'de tüm değișkenlere ait ortalamalar, standart sapma değerleri ve (Cronbach Alpha) güvenilirlik değerleri verilmiștir. Ortalamalara bakıldığında, ankete cevap veren 346 kullanıcının 1'den 5'e Likert ölçeğinin ortanca değeri olan 2,5'un üzerinde değișkenleri olduğu görülmektedir. Alfa güvenilirlik değerleri ise 0.915 ile 0.961 arasında değișmektedir. Alfa değerleri 0.70 'in üzerindedir (Nunnally \& Bernstein, 1994).

\begin{tabular}{|l|l|c|c|c|c|c|c|c|}
\hline & & Ort. & SS & CrA & $\mathbf{1}$ & $\mathbf{2}$ & $\mathbf{3}$ & $\mathbf{4}$ \\
\hline $\mathbf{1}$ & Web Sayfasına Güven & 3.25 & 1,086 &, 915 & & & & \\
\hline $\mathbf{2}$ & Canlı Destek Güven & 3,41 &, 995 &, 919 &, $588^{* *}$ & & & \\
\hline $\mathbf{3}$ & Canlı Destek Algılanan Yarar & 3,44 & 1,007 &, 953 &, $558^{* *}$ &, $792^{* *}$ & & \\
\hline $\mathbf{4}$ & Satın Alma Niyeti & 3,59 & 1,081 &, 955 &, $619^{* *}$ &, $561^{* *}$ &, $591^{* *}$ & \\
\hline $\mathbf{5}$ & Sadakat Niyeti & 3,69 &, 983 &, 961 &, $648^{* *}$ &, $593^{* *}$ &, $602^{* *}$ &, $751^{* *}$ \\
\hline
\end{tabular}

Tablo 4: Korelasyon Analizi

Korelasyon katsayı değerleri incelendiğinde tüm değişkenler arasında anlamlı bir ilişki olduğu ortaya çıkmıştır. Tablo 4'ü incelediğimizde tüm değişkenler arasında en güçlü korelasyon ilişkisinin canlı destek güven boyutu ile canlı destek algılanan yarar boyutu $(\mathrm{r}=0.792, \mathrm{p}<0.01)$ arasında olduğu görülmektedir. Yine korelasyon tablosunu incelendiğimizde tüm değişkenler arasında pozitif yönlü bir ilişki göze çarpmaktadır.

\subsubsection{Regresyon Analizi}

Araştırmada ortaya konulan hipotezlerinin test edilmesi için çoklu regresyon analizi yapılmıștır.

\subsubsection{Web Sayfasına Güvenin Yeniden Satın Alma Niyeti Boyutları Üzerindeki Etkisi}

Model 1 anlamlıdır ve bir hipotez test edilmektedir (F:213.456, $\mathrm{P}<0.01)$. Bağımsız değişkenlerin modeldeki bağımlı değişkenin varyansını açıklama oranı olan $\mathrm{R}^{2}$ değeri 0.383 olarak bulunmuştur. Yapılan regresyon analizi sonucunda web sayfasına güven ile yeniden satın olma niyeti boyutlarında satın alma niyeti $(\beta=0,383 ; p<0,01)$ arasında istatistiksel açıdan anlamlı ve pozitif yönlü bir etkinin olduğu anlaşılmıştır. Bu sonuçlara göre Hipotez 1 desteklenmiștir. Modele ilișkin regresyon analizi sonuçları tablo 5'de verilmiştir. 
Emine Aydınhan, Serhat Erat, "Web Sayfasına Güven ve Canlı Desteğin Yeniden Satın Alma Niyeti Üzerine Etkisi: Online Alışveriş Siteleri Üzerine Bir Araştırma", İstanbul Gelişim Üniversitesi Sosyal Bilimler Dergisi, 6 (GELIŞíiM-UWE 2019 Özel Sayısı), Ekim 2019, ss. 123-140.

\begin{tabular}{|l|l|l|l|}
\hline Model 1 & \multicolumn{3}{|l|}{ Yeniden Satın Alma Niyeti } \\
& \multicolumn{3}{|l|}{ Satın Alma Niyeti } \\
\hline & Beta & $\mathbf{t}$ & Sig. \\
\hline Web Sayfasına Güven &, 619 & 14,610 &, $000^{* *}$ \\
\hline $\boldsymbol{R}^{\mathbf{2}}$ & .383 & \\
$\boldsymbol{F}$ & 213.456 & \\
Sig & .000 & \\
\hline
\end{tabular}

$* * \mathrm{P}<0.01$

Tablo 5: Web Sayfasına Güvenin, Yeniden Satın Niyeti Boyutlarından Satın Alma Niyeti Üzerine Etkisi

Model 2 anlamlıdır ve bir hipotez test edilmektedir (F:248.868, $\mathrm{P}<0.01$ ). Bağımsız değișkenlerin modeldeki bağımlı değișkenin varyansını açıklama oranı olan $\mathrm{R}^{2}$ değeri 0.420 olarak bulunmuştur. Yaplan regresyon analizi sonucunda web sayfasına güven ile yeniden satın olma niyeti boyutlarından sadakat niyeti $(\beta=0,648 ; p<0,01)$ arasında istatistiksel açıdan anlamlı ve pozitif yönlü bir etkinin olduğu anlaşılmıştır. Bu sonuçlara göre Hipotez 2 desteklenmiştir. Modele ilişkin regresyon analizi sonuçları tablo 6'da verilmiștir.

\begin{tabular}{|l|l|l|l|}
\hline Model 2 & \multicolumn{3}{|l|}{ Yeniden Satın Alma Niyeti } \\
Sadakat Niyeti
\end{tabular}

$* * \mathrm{P}<0.01$

Tablo 6: Web Sayfasına Güvenin, Yeniden Satın Niyeti Boyutlarından Sadakat Niyeti Üzerine Etkisi

\section{Üzerindeki Etkisi}

3.4.3.2. Canlı Destek Boyutlarının, Yeniden Satın Alma Niyeti Boyutları

Model 3 anlamlıdır ve iki hipotez test edilmektedir (F:101.683, $\mathrm{P}<0.01$ ). Bağımsız değişkenlerin modeldeki bağımlı değișkenin varyansını açıklama oranı olan $\mathrm{R}^{2}$ değeri 0.372 olarak bulunmuştur. Yapılan regresyon analizi sonucunda canlı destek güven boyutu ile yeniden satın olma niyeti boyutlarından satın alma niyeti $(\beta=0,249 ; p<0,01)$ ve canlı destek algılanan yarar boyutu ile yeniden satın olma niyeti boyutlarından satın alma niyeti $(\beta=0,394: \mathrm{p}<0,01)$ arasında istatistiksel açıdan anlamlı ve pozitif yönlü bir etkinin olduğu anlaşılmıştır. Bu sonuçlara göre Hipotez 3 ve Hipotez 4 desteklenmiştir. Modele ilişkin çoklu regresyon analizi sonuçları tablo 7'da verilmiştir. 
Emine Aydınhan, Serhat Erat, "Web Sayfasına Güven ve Canlı Desteğin Yeniden Satın Alma Niyeti Üzerine Etkisi: Online Alışveriş Siteleri Üzerine Bir Araştırma", İstanbul Gelişim Üniversitesi Sosyal Bilimler Dergisi, 6 (GELIŞiM-UWE 2019 Özel Sayısı), Ekim 2019, ss. 123-140.

\begin{tabular}{|c|c|c|c|}
\hline \multirow[t]{2}{*}{ Model 3} & \multicolumn{3}{|c|}{$\begin{array}{l}\text { Yeniden Satın Alma Niyeti } \\
\text { Satın Alma Niyeti }\end{array}$} \\
\hline & Beta & $t$ & Sig. \\
\hline $\begin{array}{l}\text { Canlı Destek } \\
\text { Güven }\end{array}$ & ,249 & 3,559 &, $000^{* *}$ \\
\hline \begin{tabular}{|l|} 
Canlı Destek \\
Algılanan Yarar
\end{tabular} & 394 & 5.619 &, $000^{* *}$ \\
\hline \begin{tabular}{|l|}
$R^{2}$ \\
$F$ \\
Sig
\end{tabular} & \multicolumn{3}{|c|}{\begin{tabular}{|l}
.372 \\
101.683 \\
.000
\end{tabular}} \\
\hline
\end{tabular}

$* * \mathrm{P}<0.01$

Tablo 7: Canlı Destek Boyutlarının, Yeniden Satın Niyeti Boyutlarından Satın Alma Niyeti Üzerine Etkisi

Model 4 anlamlıdır ve iki hipotez test edilmektedir (F:113.721, P<0.01). Bağımsız değişkenlerin modeldeki bağımlı değişkenin varyansını açıklama oranı olan $\mathrm{R}^{2}$ değeri 0.399 olarak bulunmuştur. Yapılan regresyon analizi sonucunda canlı destek güven boyutu ile yeniden satın olma niyeti boyutlarından sadakat niyeti $(\beta=0,312 ; p<0,01)$ ve canlı destek algılanan yarar boyutu ile yeniden satın olma niyeti boyutlarından sadakat niyeti $(\beta=0,355 ; p<0,01)$ arasında istatistiksel açıdan anlamlı ve pozitif yönlü bir etkinin olduğu anlaşılmıștır. Bu sonuçlara göre Hipotez 5 ve Hipotez 6 desteklenmiștir. Modele ilişkin çoklu regresyon analizi sonuçları tablo 8'de verilmiştir.

\begin{tabular}{|c|c|c|c|}
\hline \multirow[t]{2}{*}{ Model 4} & \multicolumn{3}{|c|}{$\begin{array}{l}\text { Yeniden Satın Alma Niyeti } \\
\text { Sadakat Niyeti }\end{array}$} \\
\hline & Beta & $\mathbf{t}$ & Sig. \\
\hline $\begin{array}{l}\text { Canlı Destek } \\
\text { Güven }\end{array}$ &, 312 & 4,554 &, $000^{* *}$ \\
\hline $\begin{array}{l}\text { Canlı Destek } \\
\text { Algılanan Yarar }\end{array}$ &, 355 & 5.178 &, $000^{* *}$ \\
\hline $\begin{array}{l}R^{2} \\
F \\
\text { Sig }\end{array}$ & \multicolumn{3}{|c|}{$\begin{array}{l}.399 \\
113.721 \\
.000\end{array}$} \\
\hline
\end{tabular}

$* * \mathrm{P}<0.01$

Tablo 8: Canlı Destek Boyutlarının, Yeniden Satın Niyeti Boyutlarından Sadakat Niyeti Üzerine Etkisi

\subsubsection{Hipotezlere İlişkin Sonuçlar}

Modellere ait regresyon analizleri sonucunda elde edilen hipotez sonuçları Tablo 9'da gösterilmiştir.

\begin{tabular}{|c|l|c|}
\hline \multicolumn{2}{|l|}{ HIPPOTEZR } & SONUÇ \\
\hline $\mathrm{H}_{1}$ & $\begin{array}{l}\text { Web Sayfasına Güven boyutu Yeniden Satın Alma Niyeti boyutlarından Satın } \\
\text { Alma Niyeti boyutunu olumlu etkilemektedir. }\end{array}$ & Desteklendi \\
\hline $\mathrm{H}_{2}$ & $\begin{array}{l}\text { Web Sayfasına Güven boyutu Yeniden Satın Alma Niyeti boyutlarından } \\
\text { Sadakat Niyeti boyutunu olumlu etkilemektedir. }\end{array}$ & Desteklendi \\
\hline $\mathrm{H}_{3}$ & $\begin{array}{l}\text { Canlı Destek boyutlarından Güven boyutu Yeniden Satın Alma Niyeti } \\
\text { boyutlarından Satın Alma Niyeti boyutunu olumlu etkilemektedir. }\end{array}$ & Desteklendi \\
\hline $\mathrm{H}_{4}$ & $\begin{array}{l}\text { Canlı Destek boyutlarından Güven boyutu Yeniden Satın Alma Niyeti } \\
\text { boyutlarından Sadakat Niyeti boyutunu olumlu etkilemektedir. }\end{array}$ & Desteklendi \\
\hline $\mathrm{H}_{5}$ & $\begin{array}{l}\text { Canlı Destek boyutlarından Alglanan Yarar boyutu Yeniden Satın Alma Niyeti } \\
\text { boyutlarından Satın Alma Niyeti boyutunu olumlu etkilemektedir. }\end{array}$ & Desteklendi \\
\hline $\mathrm{H}_{6}$ & $\begin{array}{l}\text { Canlı Destek boyutlarından Alglanan Yarar boyutu Yeniden Satın Alma Niyeti } \\
\text { boyutlarından Sadakat Niyeti boyutunu olumlu etkilemektedir. }\end{array}$ & Desteklendi \\
\hline
\end{tabular}

Tablo 9: Hipotez sonuçları 
Emine Aydınhan, Serhat Erat, "Web Sayfasına Güven ve Canlı Desteğin Yeniden Satın Alma Niyeti Üzerine Etkisi: Online Alışveriş Siteleri Üzerine Bir Araştırma", İstanbul Gelişim Üniversitesi Sosyal Bilimler Dergisi, 6 (GELIŞiM-UWE 2019 Özel Sayısı), Ekim 2019, ss. 123-140.

\section{Sonuç ve Öneriler}

Günümüzde geleneksel mağaza sahipleri de dâhil hemen hemen tüm firmaların sanal kimlikleri vardır. Oluşturdukları bu sanal kimliklerde başarıyı yakalamak, rekabet avantajı sağlayabilmek açısından büyük öneme sahiptir. İşletmeler müşteriler ile tek seferlik ilișkiler değil, uzun süreli ilişkiler kurmayı amaçlamaktadır. Bu sebeple firmaların hedef kitlesini iyi tanıması, hedef kitlenin ihtiyaç ve arzularını biliyor olması gerekmektedir. Bunun yolu da tüketiciden geçmektedir. Bu sebeple literatürde tüketici davranışlarını etkileyen faktörler üzerinde birçok çalışma bulunmaktadır. Bu araştırmada, bu çalışmalardan yola çlkarak özgün bir model geliştirilmiştir. Ortaya konulan bu modele ulusal veya uluslararası literatürde bilgimiz dâhilinde rastlanılmamıştır. Yapılan analizler sonucunda web sayfasına güven ve canlı desteğin, tüketicilerin aynı sanal mağazadan tekrar satın alım niyetine etkileri ölçümlenmekte ve aralarındaki ilişkiler incelenmektedir.

Araştırmanın sonucunda elde ettiğimiz sonuçlar web sayfasına güven ve canlı desteğin, tüketicinin tekrar satın alma niyeti üzerindeki etkilerinin tespit edilmesi açısından önemli sonuçlar ortaya koymaktadır. Araştırmada aynı zamanda, web sayfasına güven ve yeniden satın alma niyeti gibi literatürde daha önce test edilen boyutların yanında, canlı destek boyutunun da etkisi ölçülmeye çalışılmıştır. Çalışma bu yönüyle özgündür. Elde edilen sonuçlara göre web sayfasına güven, canlı destek güven ve canlı destek algılanan yararın yeniden satın alma niyeti üzerinde önemli etkiye sahip olduğu ortaya çıkmaktadır. Bu sonuçlar göstermektedir ki e- perakendecinin web sitesinin güvenilir olması ve müșterin anında / doğrudan iletişime geçebileceği bir canlı destek sisteminin olması, işletmeye birçok anlamda faydası olan ve rekabet avantajı sağlayan yeniden satın alma niyeti üzerinde önemli bir rol oynamaktadır. Literatürde bu alandaki çalışmalar incelendiğinde bu araştırmanın sonuçlarını destekleyen çalışmalar olduğunu görülmektedir. G.-G. Lee and Lin (2005) güvenin çevrimiçi satın almayı teşvik ettiğini ve e-perakendecilerin satın alma konusundaki müșteri tutumlarını etkilediğini belirtmektedir. Chaudhuri and Holbrook (2001) sadakatin güven tarafından yaratılan değerli ve önemli bir ilişkiyi sürdürme ve sürdürme sürecinin devam etmesine katkıda bulunduğunu belirtmiștir.

Araştırma istatistikleri incelendiğinde yeniden satın alma niyetine etki eden en önemli unsur web sayfasına güven olarak belirlenmektedir. Güven yeniden satın alma niyeti üzerinde pozitif bir etkiye sahiptir. Aynı şekilde canlı desteğin sağlamış olduğu güven de müșterinin aynı sanal mağazadan yeniden satın alım yapmasını pozitif olarak etkilemektedir. Güvenin müşterilerin çevrimiçi satın alma niyetini olumlu yönde kesinlikle etkilediği mevcut literatürde kapsamlı olarak doğrulanmıştır (Lu et al., 2016; Mansour, Kooli, \& Utama, 2014; O. Pappas, G. Pateli, N. Giannakos, \& Chrissikopoulos, 2014; Peng, Fan, \& Hsu, 2004) Bu durum göstermektedir ki: e ticaret işletmelerinin online ortamda rekabet avantajı ve kazanç sağlamak için önemli bir faktör olan, müşterilerin aynı sanal mağazadan yeniden satın alım yapmasını sağlamak için öncelikle web sitelerinin güvenliğine dikkat etmeleri gerekmektedir. Müşteri güveni aynı zamanda beraberinde sadakati getirir ki bu da yeniden satın alma niyetine etki eden önemli faktörlerdendir. Literatürde de yer aldığı gibi mevcut müșterilerini elde tutan işletmeler başarılıdır. Web sitelerinde ve e-ticarette güvenli olduğunu hissettiren, kullanıcıları siteye bağlayan ve memnun eden işletmeler başarılıdır (C. Liu \& Arnett, 2000).

Yine araştırma istatistikleri incelendiğinde canlı destek algllanan yarar değişkeninin de yeniden satın alma niyeti üzerinde olumlu bir etkisi olduğu görülmektedir. Bu sonuçlara göre müşterilerin aynı sanal mağazadan yeniden satın alım 
Emine Aydınhan, Serhat Erat, "Web Sayfasına Güven ve Canlı Desteğin Yeniden Satın Alma Niyeti Üzerine Etkisi: Online Alışveriş Siteleri Üzerine Bir Araştırma", İstanbul Gelişim Üniversitesi Sosyal Bilimler Dergisi, 6 (GELIŞiM-UWE 2019 Özel Sayısı), Ekim 2019, ss. 123-140.

yapmasını etkileyen bir diğer önemli faktörün canlı destek sisteminin sanal mağaza içerisinde bulunmasıdır. Çok sayıda e-ticaret web sitesi, müşterileri web sitesinde tutmak için canlı sohbet sistemini desteklemektedir. Çünkü canlı sohbetlerin sonucu olarak, müşteriler çevrimiçi alışveriş deneyimine güven duymaktalar ve dönüşüm oranlarında da iyileşmeler olmaktadır. Rekabetin sürekli arttığı elektronik ticarette, işletmelerin müşterin dikkatini çekebilmeleri ve sanal mağazalarından satın alım devamlılı̆̆ını sağlayabilmeleri için bu boyutlara dikkat etmeleri ve kendilerini bu konularda geliștirmeleri bir zorunluluktur.

\subsection{Araştırma Kısıtları ve Gelecek Çalışmalar İçin Öneriler}

Yapılan bu çalıșmanın bulgularındaki en önemli kısıt, çalıșmanın sadece bir ülkeyi ve belirli bir grubu kapsamasıdır. Web sitesi kullanıcı niyetleri farklı kültür, ülke, bölge ve eğitim seviyelerinde değișiklik gösterebilmektedir. Gelecek çalışmalarda web sayfasına olan güvenin yeniden satın alma niyeti üzerindeki etkisinde canlı desteğin ara değişken etkisi incelenebilir. Bu değişkenlere ek olarak müşterilerin online alışveriş sitelerini tercih etmelerinde etkili olan fiyat avantajı ve marka algısı de gelecek çalıșmalarda eklenerek fiyat değișkeninin ve marka algısının mevcut değișkenlerimize etkisi incelenebilir.

\section{KAYNAKÇA}

ADJEI, M. T., NOBLE, S. M., \& NOBLE, C. H. (2010). The influence of C2C communications in online brand communities on customer purchase behavior. Journal of the Academy of Marketing Science, 38(5), 634-653.

AHMED, I., SHAUKAT, M. Z., NAWAZ, M. M., AHMED, N., \& USMAN, A. (2011). Determinants of the satisfaction and repurchase intentions of users of short messenger services (SMAS): A study in the Telecom sector of Pakistan. International Journal of Management, 28(3), 763.

ALTINIȘIK, İ., \& BILGE, F. A. (2001). Yem bin yıla girerken ticaretin değișen yüzü: e ticaret. Selçuk Üniversitesi Sosyal Bilimler MYO Dergisi, 4(1), 77-88.

ANDERSON, E., \& WEITZ, B. (1992). The use of pledges to build and sustain commitment in distribution channels. Journal of marketing research, 18-34.

AVCI, E., BARAN, G. G., \& ÖZOĞUL, G. Seyahat acentalarının hizmetlerine yönelik e-şikâyetlerin tekrar satın alma (ma) niyeti çerçevesinde çözümlenmesi.

AYAZLAR, R. A., \& YÜKSEL, A. (2012). Web sitesi kalitesi, risk ve güven: Bilişsel çelişki ve tüketim sonrası davranışlar üzerine etkileri. Seyahat ve Otel İşletmeciliği Dergisi, 9(1), 1-28.

CENFETELLI, R. T., BENBASAT, I., \& AL-NATOUR, S. (2008). Addressing the what and how of online services: Positioning supporting-services functionality and service quality for business-to-consumer success. Information Systems Research, 19(2), 161-181.

CHATTARAMAN, V., KWON, W.-S., \& GILBERT, J. E. (2012). Virtual agents in retail web sites: Benefits of simulated social interaction for older users. Computers in Human Behavior, 28(6), 2055-2066.

CHAUDHURI, A., \& HOLBROOK, M. B. (2001). The chain of effects from brand trust and brand affect to brand performance: the role of brand loyalty. Journal of marketing, 65(2), 81-93.

CHENG, H.-H., \& HUANG, S.-W. (2013). Exploring antecedents and consequence of online group-buying intention: An extended perspective on theory of planned behavior. International Journal of Information Management, 33(1), 185-198. 
Emine Aydınhan, Serhat Erat, “Web Sayfasına Güven ve Canlı Desteğin Yeniden Satın Alma Niyeti Üzerine Etkisi: Online Alışveriş Siteleri Üzerine Bir Araştırma", İstanbul Gelişim Üniversitesi Sosyal Bilimler Dergisi, 6 (GELIŞiM-UWE 2019 Özel Sayısı), Ekim 2019, ss. 123-140.

CHIU, C.-M., CHANG, C.-C., CHENG, H.-L., \& FANG, Y.-H. (2009). Determinants of customer repurchase intention in online shopping. Online Information Review, 33(4), 761-784.

COŞKUN, A. G. D. N. (2004). Elektronik ticaretin gelişiminde temel dinamikler ve gelişimi önündeki engeller. Çukurova Üniversitesi Sosyal Bilimler Enstitüsü Dergisi, 13(2).

CULNAN, M. J., \& ARMSTRONG, P. K. (1999). Information privacy concerns, procedural fairness, and impersonal trust: An empirical investigation. Organization science, 10(1), 104-115.

DAYAL, S., LANDESBERG, H., \& ZEISSER, M. (2003). How to build trust online. Trust in the Network Economy, 89-95.

DEMIRDÖĞMEZ, M., GÜLTEKIN, N., \& TAȘ, H. Y. (2018). Türkiye'de e-ticaret sektörünün yıllara göre gelişimi. OPUS Uluslararası Toplum Araştırmaları Dergisi, 8(15), 2216-2236.

EID, M. I. (2011). Determinants of e-commerce customer satisfaction, trust, and loyalty in Saudi Arabia. Journal of electronic commerce research, 12(1), 78.

ELMORSHIDY, A. (2013). Applying the technology acceptance and service quality models to live customer support chat for e-commerce websites. Journal of Applied Business Research, 29(2), 589-595.

ERÇETIN, C. (2015). Elektronik ticarette tüketicilerin satın alma davranış ve tercihlerini etkileyen unsurlar: E-ticaret siteleri üzerine bir çalışma. Doğuș Üniversitesi Sosyal Bilimler Enstitüsü,

FLANAGIN, A. J., \& METZGER, M. J. (2007). The role of site features, user attributes, and information verification behaviors on the perceived credibility of webbased information. New media \& society, 9(2), 319-342.

FOGG, B., MARSHALL, J., LARAKI, O., OSIPOVICH, A., VARMA, C., FANG, N., . . . SWANI, P. (2001). What makes Web sites credible?: a report on a large quantitative study. Paper presented at the Proceedings of the SIGCHI conference on Human factors in computing systems.

FRIEDMAN, B., KHAN JR, P. H., \& HOWE, D. C. (2000). Trust online. Communications of the ACM, 43(12), 34-40.

GEFEN, D., KARAHANNA, E., \& STRAUB, D. W. (2003). Trust and TAM in online shopping: An integrated model. MIS quarterly, 27(1), 51-90.

GRABNER-KRAEUTER, S. (2002). The role of consumers' trust in onlineshopping. Journal of Business Ethics, 39(1-2), 43-50.

GUPTA, S., \& KIM, H.-W. (2007). The moderating effect of transaction experience on the decision calculus in on-line repurchase. International Journal of Electronic Commerce, 12(1), 127-158.

HAR LEE, C., CYRIL EZE, U., \& OLY NDUBISI, N. (2011). Analyzing key determinants of online repurchase intentions. Asia Pacific Journal of Marketing and Logistics, 23(2), 200-221.

HELLIER, P. K., GEURSEN, G. M., CARR, R. A., \& RICKARD, J. A. (2003). Customer repurchase intention: A general structural equation model. European Journal of Marketing, 37(11/12), 1762-1800.

HOFFMAN, D. L., \& NOVAK, T. P. (1996). Marketing in hypermedia computermediated environments: Conceptual foundations. The Journal of Marketing, 50-68.

HOFFMAN, D. L., NOVAK, T. P., \& PERALTA, M. (1999). Building consumer trust online. Communications of the ACM, 42(4), 80-85.

HSIN CHANG, H., \& WEN CHEN, S. (2008). The impact of online store environment cues on purchase intention: Trust and perceived risk as a mediator. Online Information Review, 32(6), 818-841. 
Emine Aydınhan, Serhat Erat, “Web Sayfasına Güven ve Canlı Desteğin Yeniden Satın Alma Niyeti Üzerine Etkisi: Online Alışveriş Siteleri Üzerine Bir Araştırma", İstanbul Gelişim Üniversitesi Sosyal Bilimler Dergisi, 6 (GELIŞiM-UWE 2019 Özel Sayısı), Ekim 2019, ss. 123-140.

JARVENPAA, S. L., TRACTINSKY, N., \& VITALE, M. (2000). Consumer trust in an Internet store. Information Technology and Management, 1(1-2), 45-71.

JIANG, Z., CHAN, J., TAN, B. C., \& CHUA, W. S. (2010). Effects of interactivity on website involvement and purchase intention. Journal of the Association for information systems, 11(1), 1.

KHALIFA, M., \& LIU, V. (2007). Online consumer retention: contingent effects of online shopping habit and online shopping experience. European Journal of Information Systems, 16(6), 780-792.

KIM, H., SUH, K.-S., \& LEE, U.-K. (2013). Effects of collaborative online shopping on shopping experience through social and relational perspectives. Information \& Management, 50(4), 169-180.

KÖKSAL, Y., \& PENEZ, S. (2015). An investigation of the important factors influence web trust in online shopping. Journal of Marketing and Management, 6(1), 28.

KUMAR, N., SCHEER, L. K., \& STEENKAMP, J.-B. E. (1995). The effects of perceived interdependence on dealer attitudes. Journal of marketing research, 348-356.

LEE, A., \& JEONG, M. (2010). Effects of e-servcescape on customers flow experiences. Journal of Hospitality and Tourism Technology, 3(1), 47-59.

LEE, G.-G., \& LIN, H.-F. (2005). Customer perceptions of e-service quality in online shopping. International Journal of Retail \& Distribution Management, 33(2), 161176.

LEE, M. K., \& TURBAN, E. (2001). A trust model for consumer internet shopping. International Journal of Electronic Commerce, 6(1), 75-91.

LIN, H.-H., \& WANG, Y.-S. (2006). An examination of the determinants of customer loyalty in mobile commerce contexts. Information \& Management, 43(3), 271282.

LIU, C., \& ARNETT, K. P. (2000). Exploring the factors associated with Web site success in the context of electronic commerce. Information \& Management, 38(1), 23-33.

LIU, T.-H. (2012). Effect of e-service quality on customer online repurchase intentions: Lynn University.

LOIACONO, E. T., WATSON, R. T., \& GOODHUE, D. L. (2002). WebQual: A measure of website quality. Marketing theory and applications, 13(3), 432-438.

LU, B., FAN, W., \& ZHOU, M. (2016). Social presence, trust, and social commerce purchase intention: An empirical research. Computers in Human Behavior, 56, 225-237.

MANSOUR, K. B., KOOLI, K., \& UTAMA, R. (2014). Online trust antecedents and their consequences on purchase intention: An integrative approach. Journal of Customer Behaviour, 13(1), 25-42.

MAVLANOVA, T., \& BENBUNAN-FICH, R. (2010). Counterfeit products on the internet: The role of seller-level and product-level information. International Journal of Electronic Commerce, 15(2), 79-104.

MCKNIGHT, D. H., CHOUDHURY, V., \& KACMAR, C. (2002). Developing and validating trust measures for e-commerce: An integrative typology. Information Systems Research, 13(3), 303-359.

MCLEAN, G., \& OSEI-FRIMPONG, K. (2017). Examining satisfaction with the experience during a live chat service encounter-implications for website providers. Computers in Human Behavior, 76, 494-508.

MCLEAN, G., \& WILSON, A. (2016). Evolving the online customer experience... is there a role for online customer support? Computers in Human Behavior, 60, 602-610.

MONTOYA-WEISS, M., VOSS, G., \& GREWAL, D. (2000). Bricks to Clicks: What Drives Customer Use of the Internet in a Multichannel Enviroment, Working Paper, Caroline State University. 
Emine Aydınhan, Serhat Erat, “Web Sayfasına Güven ve Canlı Desteğin Yeniden Satın Alma Niyeti Üzerine Etkisi: Online Alışveriş Siteleri Üzerine Bir Araştırma", İstanbul Gelişim Üniversitesi Sosyal Bilimler Dergisi, 6 (GELIŞiM-UWE 2019 Özel Sayısı), Ekim 2019, ss. 123-140.

NUNNALLY, J., \& BERNSTEIN, I. (1994). Psychometric Theory 3rd edition (MacGraw-Hill, New York).

O. PAPPAS, I., G. PATELI, A., N. GIANNAKOS, M., \& CHRISSIKOPOULOS, V. (2014).

Moderating effects of online shopping experience on customer satisfaction and repurchase intentions. International Journal of Retail \& Distribution Management, 42(3), 187-204.

OU, C. X., PAVLOU, P. A., \& DAVISON, R. (2014). Swift guanxi in online marketplaces: The role of computer-mediated communication technologies. MIS quarterly, 38(1), 209-230.

PARASURAMAN, A., BERRY, L. L., \& ZEITHAML, V. A. (1991). Refinement and reassessment of the SERVQUAL scale. Journal of retailing, 67(4), 420.

PARASURAMAN, A., ZEITHAML, V. A., \& MALHOTRA, A. (2005). ES-QUAL: A multiple-item scale for assessing electronic service quality. Journal of service research, 7(3), 213-233.

PAVLOU, P. A., LIANG, H., \& XUE, Y. (2007). Understanding and mitigating uncertainty in online exchange relationships: A principal-agent perspective. MIS quarterly, 105-136.

PENG, K.-F., FAN, Y.-W., \& HSU, T.-A. (2004). Proposing the content perception theory for the online content industry-a structural equation modeling. Industrial Management \& Data Systems, 104(6), 469-489.

QURESHI, I., FANG, Y., RAMSEY, E., MCCOLE, P., IBBOTSON, P., \& COMPEAU, D. (2009). Understanding online customer repurchasing intention and the mediating role of trust-an empirical investigation in two developed countries. European Journal of Information Systems, 18(3), 205-222.

REICHHELD, F., \& SASSER, J. (1996). Zero defections: quality come to services, Harvard Bussines Review 68 (5), 105-111. In.

SCHURR, P. H., \& OZANNE, J. L. (1985). Influences on exchange processes: Buyers' preconceptions of a seller's trustworthiness and bargaining toughness. Journal of consumer research, 11(4), 939-953.

SHARMA, N., \& PATTERSON, P. G. (2000). Switching costs, alternative attractiveness and experience as moderators of relationship commitment in professional, consumer services. International journal of service industry management, 11(5), 470-490.

SHIAU, W.-L., \& LUO, M. M. (2012). Factors affecting online group buying intention and satisfaction: A social exchange theory perspective. Computers in Human Behavior, 28(6), 2431-2444.

SHIN, J. I., CHUNG, K. H., OH, J. S., \& LEE, C. W. (2013). The effect of site quality on repurchase intention in Internet shopping through mediating variables: The case of university students in South Korea. International Journal of Information Management, 33(3), 453-463.

SOLOMON, M. R., SURPRENANT, C., CZEPIEL, J. A., \& GUTMAN, E. G. (1985). A role theory perspective on dyadic interactions: the service encounter. The Journal of Marketing, 99-111.

SRINIVASAN, S. S., ANDERSON, R., \& PONNAVOLU, K. (2002). Customer loyalty in e-commerce: an exploration of its antecedents and consequences. Journal of retailing, 78(1), 41-50.

SUM CHAU, V., \& KAO, Y.-Y. (2009). Bridge over troubled water or long and winding road? Gap-5 in airline service quality performance measures. Managing Service Quality: An International Journal, 19(1), 106-134.

TOMBS, A., \& MCCOLL-KENNEDY, J. R. (2003). Social-servicescape conceptual model. Marketing theory, 3(4), 447-475. 
Emine Aydınhan, Serhat Erat, "Web Sayfasına Güven ve Canlı Desteğin Yeniden Satın Alma Niyeti Üzerine Etkisi: Online Alışveriş Siteleri Üzerine Bir Araştırma", İstanbul Gelişim Üniversitesi Sosyal Bilimler Dergisi, 6 (GELIŞiM-UWE 2019 Özel Sayısı), Ekim 2019, ss. 123-140.

TSAI, H.-T., \& HUANG, H.-C. (2007). Determinants of e-repurchase intentions: An integrative model of quadruple retention drivers. Information \& Management, 44(3), 231-239.

TUĞCU, Ş. T. (2003). Tüketim kültüründe satın alma davranışının oluşması.

TUREL, O., \& CONNELLY, C. E. (2013). Too busy to help: Antecedents and outcomes of interactional justice in web-based service encounters. International Journal of Information Management, 33(4), 674-683.

TÜİK. (2018). TÜIKK Hanehalkı Bilişim Teknolojileri (BT) Kullanım Araştırması, 2018 (Erişim Tarihi: 03.02.2019)

http://www.tuik.gov.tr/PreHaberBultenleri.do?id=27819.

YILDIRIM, L. (2017). Online alışveriş sitelerinde uygulanan canlı destek sistemlerinin tüketicilerde olușturduğu güvene etkisi: bir araștırma.

YOO, B., \& DONTHU, N. (2001). Developing and validating a multidimensional consumer-based brand equity scale. Journal of Business Research, 52(1), 1-14.

ZEREN, D., \& GOKDAGLI, N. (2017). Marka Prestiji ve Marka Kredibilitesinin Satın Alma Niyeti Üzerindeki Etkisi. Isşletme ve Íktisat Çalışmaları Dergisi, 5(2), 91-102.

\section{Summary}

Marketing has gone through many stages until today. But with the development and become popular on the internet, it has ushered in a new age for marketing. In this new digital age, e-commerce websites have become popular, e-retailers have increased. With the development of technology and the become popular of the internet, globalization has come to exist and communication has increased. People have become easily accessible to the whole world. While this process is developing, some concepts have started to gain importance for businesses. Some of these are web page quality, trust, customer satisfaction, live support, brand loyalty, customer loyalty, intention to buy, repurchase intention. With the importance of these concepts, the businesses focused on these concepts and tried to develop themselves in many ways.

In addition, with the rapid become popular of the internet and the development of technology, competition in e-commerce has also increased. It is not easy for businesses to attract the attention of customers and gain their trust in this increasing competition. In addition, the concept of profit making, which is one of the purposes of businesses' existence, depends on making sales and providing its continuity. Therefore, businesses should win customers and they are required to providing them to repurchase from the website again. One way to achieve this is to provide customer satisfaction. Businesses should provide that they are real people who can communicate to customers in the virtual environment as soon as they need it. The purpose of this study is to assess the impact of trust on the website and the impact of live support on the concept of repurchase and the relationship between these concepts. Based on the previous studies, the effects of trust, live support and repurchase intention to the web page and the relationship between them are examined with 6 hypothesis tests. 